TITLE:

\title{
Integrating remote sensing and GIS for prediction of rice protein contents
}

\section{AUTHOR(S):}

Ryu, Chanseok; Suguri, Masahiko; lida, Michihisa; Umeda, Mikio; Lee, Chungkeun

\section{CITATION:}

Ryu, Chanseok ...[et al]. Integrating remote sensing and GIS for prediction of rice protein contents. Precision Agriculture 2011, 12(3): 378-394

\section{ISSUE DATE:}

2011-06

URL:

http://hdl.handle.net/2433/141863

\section{RIGHT:}

The final publication is available at www.springerlink.com; This is not the published version. Please cite only the published version.; この論文 は出版社版でありません。引用の際には出版社版をご確認ご利用くだ さい。 


\title{
Integrating remote sensing and GIS for prediction of rice protein contents
}

\author{
Chanseok RYU ${ }^{1 *} \cdot$ Masahiko SUGURI ${ }^{1} \cdot$ Michihisa IIDA $^{1} \cdot$ Mikio UMEDA $^{2}$ \\ - Chungkeun $\mathrm{LEE}^{3}$
}

(1) Environmental Science and Technology, Graduate School of Agriculture Kyoto University, Kitashirakawa Oiwake-cho, Sakyo-ku, Kyoto, 606-8502, Japan

(2) Kyoto University, Yoshida Hon-machi, Sakyo-ku, Kyoto, 606-8501, Japan

(3) National Academy of Agricultural Science, RDA, Suwon, 441-707, Korea

*Corresponding author

e-mail: ryu@elam.kais.kyoto-u.ac.jp

Tel.: +81-75-753-6317

Fax: +81-75-753-6167

\section{Abstract}

In this study, protein content (PC) of brown rice before harvest was established by remote sensing (RS) and analyzed to select the key management factors that cause variation of PC using a GIS database. The possibility of finding out the key management factors using GreenNDVI was tested by combining RS and a GIS database. The study site was located at Yagi basin (Japan) and PC for seven districts (85 fields) in 2006 and nine districts (73 fields) in 2007 was investigated by a rice grain taste analyzer. There was spatial variability between districts and temporal variability within the same fields. PC was predicted by the average of GreenNDVI at sampling points (Point GreenNDVI) and in the field (Field GreenNDVI). The accuracy of the Point GreenNDVI model $\left(r^{2}>0.424\right.$, RMSE $<0.256 \%)$ was better than for the Field GreenNDVI model $\left(r^{2}>0.250\right.$, RMSE $<0.298 \%)$. A general-purpose model $\left(r^{2}=0.392, \mathrm{RMSE}=0.255 \%\right)$ was established using two years data. In the GIS database, PC was separated into two parts to compare the difference in PC between the upper (mean+0.5S.D.) and lower (mean-0.5S.D.) parts. Differences in PC were significant depending on the effective cumulative temperature (ECT) from transplanting to harvest (Factor 4) in 2007 but not in 2006. Because of the difference in ECT depending on vegetation term (from transplanting to sampling), PC was separated into two groups based on the mean value of ECT as the upper (UMECT) and lower (LMECT) groups. In 2007, there were significant differences in PC at LMECT group between upper and lower parts depending on the ECT from transplanting to last top-dressing (Factor 2), the amount of nitrogen fertilizer at top-dressing (Factor 3) and Factor 4. When the farmers would have changed their field management, it would have been possible to decrease protein contents. Using the 
combination of RS and GIS in 2006, it was possible to select the key management factor by the difference in the Field GreenNDVI.

Keywords: remote sensing, geographic information system, protein content, key management factors

\section{Introduction}

Over the last four decades, the grain yield of rice has increased from $217 \mathrm{~kg} / \mathrm{ha}$ to $423 \mathrm{~kg} / \mathrm{ha}$ (FAOSTAT, 2007). Recently, the farmers in northeast Asia, northern part of China, Japan, Korea and Taiwan have focused on not only grain yield but also grain quality. However, it is difficult to control the quality of rice, because there are several factors that influence it, such as physical (Martin and Fitzgerald 2002), chemical (Endo et al. 1966) and genetic parameters (Kennedy and Burlingame 2003). There are several chemical parameters, such as protein, amylose (or amylopectin) and fatty acid contents. The rice quality improves with a decrease in contents of protein, amylose and fatty acid. Generally, fatty acid is affected by the term of storage, but protein and amylose contents are affected by management conditions such as variety, soil properties, weather condition and field management (Ryu et al., 2004). The amylose contents are mainly affected by varieties and soil condition (Koutroubas et al. 2004), but the protein contents (PCs) are affected by temperature during ripening stage (Matsue 1995; Wada et al. 2002), amount of nitrogen fertilizer (Ryu et al. 2005), water management (Chen et al. 2003) and optimal timing for transplanting (Ueda et al., 1998) or harvest (Matsue et al., 1991). However, the PC studies were experiments with small plots or pot cultivation, with several doses of nitrogen fertilizer, and with controlled environmental parameters. Therefore, it is necessary to investigate how PCs are affected by general conditions that are not artificially controlled and those conditions that have a mutual influence at the same time.

Remote sensing technology is a very useful tool for gathering much information simultaneously. There have been several research studies on rice quality, such as monitoring at rice-drying facilities using NIR sensors (Kawamura et al. 2003) and the prediction of PCs at ripening stage using satellite (Asaka and Shiga 2003).

However, there is still a lack of research for estimating PCs of rice by remote sensing, in comparison with other crops such as maize (Volkers et al. 2003), barley (Pettersson et al. 2006) and wheat (Hansen et al. 2002). In our previous research at the experimental field with several doses of nitrogen fertilizer, it was possible to predict the PCs of brown rice using GreenNDVI at heading stage. In the case of hyperspectral imaging, it was also possible to predict PCs by partial least square regression (PLSR) models (Ryu et al. 2007). 
Although much information is gathered by remote sensing technology, it is difficult to find the key management factor because each field has varying conditions such as timing and period of midseason drainage, timing and amount of nitrogen fertilizer application, and timing of harvest. For this kind of study, geographic information systems (GIS) are highly suitable. They have evolved largely by innovations created in one application of GIS being shared and built upon in subsequent applications (Pierce and Clay 2007). GIS have become rapidly becoming highly important tools for natural resource research and management (Iverson and Risser 1987). GIS has been popularly applied in agriculture, such as groundwater recharge estimation and regionalization (Sophocleous 1992), regional distribution maps for heavy metals (Facchinelli et al. 2001), scheduling and monitoring of irrigation delivery for rice irrigation systems (Rowshon et al. 2003). Therefore, it is important to construct the database for field management information to find out and analyze the key management factors not only for grain yield but also grain quality.

Therefore, using remote sensing and GIS technology, it might be possible to establish a prediction model for PCs and to search out the key management factors that affect PCs at harvest. The objectives of this study are 1) to make a prediction model of PC for rice using airborne remote sensing, 2) to search out the key management factor/s that cause differences of PC using a GIS database and 3) to find out the key management factors by GreenNDVI using the combination of RS and GIS.

\section{Materials and Methods}

\section{Study site}

The study site was located in Yagi Town, Nantan City, Kyoto Prefecture, Japan $\left(135^{\circ} 54^{\prime} \mathrm{E}, 35^{\circ} 09^{\prime} \mathrm{N}\right.$ and $120 \mathrm{~m}$ above sea level). The average annual temperature, amount of rainfall and cumulated sunshine hours over three decades were $12.9^{\circ} \mathrm{C}$, $1541 \mathrm{~mm}$, and 1633 hours $\left(13.8{ }^{\circ} \mathrm{C}, 1563 \mathrm{~mm}\right.$ and 1450 hours in 2006 and $14.1{ }^{\circ} \mathrm{C}, 1241 \mathrm{~mm}$ and 1580 hours in 2007) (JMA, 2007). The soil types are mainly Typical Gray Lowland and locally Typical Gley (Nagatsuka and Okazaki, 1990). There are 14 districts in the Yagi basin area with 450 ha of paddy fields and the sizes of fields differ from less than 0.1 ha to 1 ha (Fig. 1). However, 220 ha of fields lie fallow because of set-aside policy of the Japanese government. Therefore, there were 230 ha of arable paddy fields in 2006. The tested variety was KINU-HIKARI, which is the early growing variety in this region and was cultivated on 121 ha in 2006 (54\% of arable paddy fields). The protein contents (PCs) of 86 fields (7 districts, 21 ha, 17\% of KINU-HIKARI fields) in 2006 and 86 fields (9 districts, 23 ha, 19\% of KINU-HIKARI fields) in 2007 were investigated around one week before harvest. 


\section{Remote sensing}

The images of the study site consisted of four flight paths with $60 \%$ of overlap and were taken around eleven o'clock on September 9 in 2006 and on September 5 in 2007 (Pasco Co., Ltd., Tokyo, Japan) by the airborne digital sensor ADS40 (Leica Geosystems, Heerbrugg, Switzerland), providing a blue (430-480 nm), green $(535-585 \mathrm{~nm})$, red $(610-660 \mathrm{~nm})$ and near infrared (NIR, 835-885 $\mathrm{nm}$ ) bands. The spatial resolution on the ground which depends on the altitude of the airplane (Hache et al. 2005) was $0.0625 \mathrm{~m}^{2}$ in 2006 and $0.04 \mathrm{~m}^{2}$ in 2007. In our previous research, GreenNDVI was found to be more suitable to predict PCs at harvest than NDVI (Ryu et al. 2007). Reflectance panels $\left(16.2 \mathrm{~m}^{2}\right.$ ) with $50 \%$ and $75 \%$ of gray level were set on the middle of each district to compensate illumination and atmospheric effects; the revised reflectance was calculated by Eq. (1). GreenNDVI of each field and sampling point were calculated using ENVI 4.2 (ITT Co., Boulder, USA), as shown in Eq. (2).

$$
\begin{gathered}
\text { Revised Reflectanc e }=\frac{D N_{\text {bandof Rice }}}{D N_{\text {bandof Reflectance panel }}} \\
\text { GreenNDVI }=\frac{\left(R_{N I R}-R_{\text {Green }}\right)}{\left(R_{N I R}+R_{\text {Green }}\right)}
\end{gathered}
$$

where, $D N_{\text {band }}$ means the digital number of each band and $R_{\text {band }}$ means the revised reflectance of each band.

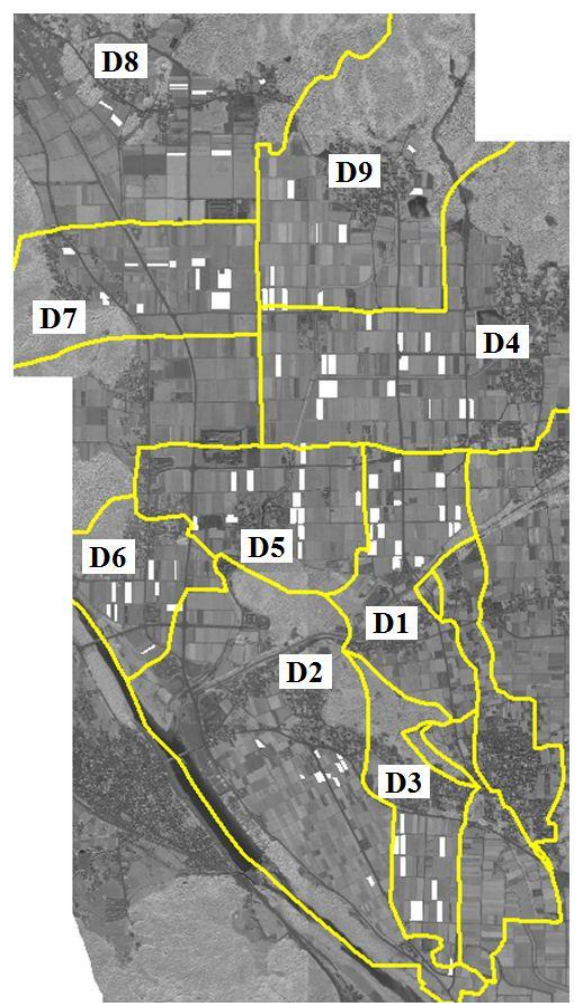

Fig. 1. Sampling fields and districts at Yagi-Town 
The simple linear regression models were established using the data of PCs and GreenNDVI value. Two types of PC prediction model were compared; 1) the Point GreenNDVI model, which is established by the average data of GreenNDVI values at each sampling point and the samples of PCs in 2007 and 2) the Field GreenNDVI model, which is established by the average of GreenNDVI values in each field and the samples of PCs in 2006 and 2007. The accuracy of the model was quantified with the Root Mean Squared Error (RMSE) (Hansen and Schjoerring 2003), as shown in Eq. (3).

$$
R M S E=\sqrt{\frac{\sum_{i=1}^{n}\left(\hat{y}_{i}-y_{i}\right)^{2}}{n}}
$$

where, $\hat{y}_{i}$ and $y_{i}$ are the predicted and measured values of the sample I and $n$ is the number of samples.

\section{Sampling of protein contents and analysis}

Approximately one week before harvest, six to eight rice plants $\left(0.38-0.6 \mathrm{~m}^{2}\right)$ were harvested around the center of each field and the sampling position was measured by GPS BR-355 (GlobalSat Technology, Chung-Ho, Taiwan). The samples were threshed and dried to about $15 \%$ moisture content. Afterwards they were husked to brown rice and sorted by a $1.9 \mathrm{~mm}$ mesh. Depending on the amount of brown rice, each sample was separated into several groups of $200 \mathrm{~cm}^{3}$ and then these were measured by a rice grain taste analyzer RCTA11A (Satake Co., Hiroshima, Japan). Rice taste, amylose contents, protein contents, fatty acid and moisture contents in each field were calculated by the average value of those groups (Ryu et al. 2005). The spatial variation for each district and the temporal variation for each year at the same district were checked using Duncan's multiple comparisons with SPSS version 13 (SPSS Inc., Chicago, USA).

\section{GIS database}

A series of thematic layers and tables were organized by ArcGIS Desktop 9.1 (ESRI, Redlands, USA) to facilitate a selection of the key management factors affecting PCs at harvest. Key management factors are those which the farmer can control easily by varying the timing and the amount applied in field management. Those suggested are the following; the effective cumulative temperature (ECT) from transplanting date to first top-dressing date (Factor 1), the ECT from transplanting date to last top-dressing date (Factor 2), the total amount of nitrogen fertilizer at top-dressing (Factor 3), and the ECT from transplanting to harvest (Factor 4). 
The ratio-interval values of GreenNDVI were scaled to byte values ranging from 0 to 255 to extract the average of GreenNDVI values in the fields and those at the sampling points by ArcGIS software. The GreenNDVI image, which was a raster file, was used as base map while the district file was constructed from the digital map (1:25000) (Geographical Survey Institute, Tsukuba, Japan) as a shape file. The field shape files of each field were measured by the GPS DG-100 (GlobalSat Technology, Chung-Ho, Taiwan) to calculate the average values of GreenNDVI in the field. The point shape files of each field in 2007 were constructed from the GPS data of each sampling point to calculate the average values of GreenNDVI at the sampling point.

The information table data (database file) that was constructed from the field management information for each field was provided by the farmers, such as the date of transplanting, the date and amount of nitrogen fertilizer application and the date of harvest. The weather conditions were calculated using data from the Japan Meteorological Agency (JMA, 2007). The shape files were linked to the database files using the function of the relationship class to sort out the specified data by the mutual search, such as the restricted range of PCs with the specified weather conditions.

\section{Results and discussions}

\section{Analysis of protein contents}

The average PC of each district was compared with that of other districts to determine whether PC varied spatially across the study area (Table 1). The average PC of brown rice for each district in 2007 was less than that in 2006, except for district 1 . The PC of district 1 was significantly different from that of district 2, 4 and 5 in 2006. In 2007, the PC of district 1 was also significantly different from that of district 6 and 7.

Table 1 Descriptive statistics for protein contents in 2006 and 2007

\begin{tabular}{|c|c|c|c|c|c|c|c|c|c|c|}
\hline & \multicolumn{5}{|c|}{ Protein contents in 2006} & \multicolumn{5}{|c|}{ Protein contents in 2007} \\
\hline & $\mathrm{N}$ & $\mathrm{N}_{1}$ & $\mathrm{~N}_{2}$ & Mean of $\mathrm{N}$ & SD of $N$ & $\mathrm{~N}$ & $\mathrm{~N}_{1}$ & $\mathrm{~N}_{2}$ & Mean of $\mathrm{N}$ & SD of $N$ \\
\hline District 1 & 15 & 14 & 14 & 7.48 & 0.27 & 13 & 10 & 0 & 7.73 & 0.43 \\
\hline District 2 & 15 & 15 & 15 & $7.68^{*}$ & 0.26 & 9 & 8 & 9 & 7.48 & 0.23 \\
\hline District 3 & 10 & 9 & 10 & 7.56 & 0.41 & 10 & 9 & 10 & 7.54 & 0.42 \\
\hline District 4 & 16 & 14 & 16 & $7.67^{*}$ & 0.32 & 15 & 15 & 15 & 7.58 & 0.33 \\
\hline District 5 & 10 & 9 & 10 & $7.85^{*}$ & 0.36 & 9 & 9 & 9 & 7.43 & 0.32 \\
\hline District 6 & 10 & 0 & 10 & 7.58 & 0.37 & 9 & 9 & 9 & $7.33^{*}$ & 0.44 \\
\hline District 7 & 10 & 8 & 10 & 7.78 & 0.41 & 9 & 7 & 9 & $7.23^{*+}$ & 0.26 \\
\hline District 8 & & & & & & 3 & 2 & 3 & 7.48 & 0.60 \\
\hline District 9 & & & & & & 9 & 6 & 9 & 7.56 & 0.41 \\
\hline Total & 86 & 69 & 85 & 7.62 & 0.35 & 86 & 75 & 73 & 7.50 & 0.38 \\
\hline
\end{tabular}


However, the PC of district 1 was lower than other districts in 2006 but higher in 2007. Difference in PC between district 4 and 7 was also significant in 2007.

Therefore, PCs for the same fields in each district during two years and the average of field management factors in each district were compared to analyze the temporal variability (Table 2). There were significant differences of PC in district 1 and 7 between 2006 and 2007. It was also shown that the PCs in 2006 were better than in 2007 at the same fields in each district. Although it was difficult to find out the reasons for temporal variability, there were differences in PCs for district 7 in spite of the same field management over two years.

Table 2 Information of field management for the same fields during two years

\begin{tabular}{cccccccccccccccc}
\hline $\mathrm{D}$ & $\mathrm{Y}$ & FD & A & TD & FD & A & FD & A & FD & A & TNF & SD & HD & P & SD \\
\hline 1 & 06 & $5 / 25$ & 4.0 & $5 / 27$ & $6 / 3$ & 0.3 & $7 / 16$ & 2.8 & $7 / 28$ & 1.9 & 8.7 & $9 / 14$ & $9 / 16$ & 7.5 & 0.29 \\
$(\mathrm{n}=12)$ & 07 & & & $5 / 30$ & & & & & & & & $9 / 13$ & $9 / 17$ & $7.8^{*}$ & 0.41 \\
2 & 06 & $5 / 21$ & 3.8 & $6 / 4$ & $7 / 5$ & 0.3 & $7 / 20$ & 0.9 & $8 / 3$ & 1.8 & 6.5 & $9 / 10$ & $9 / 16$ & 7.6 & 0.24 \\
$(\mathrm{n}=9)$ & 07 & $6 / 3$ & 4.2 & $6 / 4$ & $6 / 15$ & 0.2 & $7 / 13$ & 2.0 & $7 / 25$ & 1.8 & 8.1 & $9 / 14$ & $9 / 22$ & 7.5 & 0.21 \\
3 & 06 & $6 / 1$ & 4.7 & $6 / 5$ & $6 / 8$ & 0.9 & $7 / 17$ & 2.6 & $7 / 30$ & 1.6 & 9.7 & $9 / 14$ & $9 / 19$ & 7.6 & 0.62 \\
$(\mathrm{n}=4)$ & 07 & $6 / 1$ & 5.6 & $6 / 3$ & $7 / 21$ & 2.5 & $8 / 1$ & 1.8 & & & 9.8 & $9 / 20$ & $9 / 23$ & 7.3 & 0.31 \\
4 & 06 & $5 / 27$ & 3.5 & $5 / 28$ & $5 / 30$ & 0.2 & $7 / 22$ & 2.0 & $7 / 31$ & 1.5 & 7.0 & $9 / 10$ & $9 / 19$ & 7.6 & 0.35 \\
$(\mathrm{n}=14)$ & 07 & $5 / 26$ & 4.0 & $5 / 31$ & $6 / 4$ & 1.6 & $7 / 16$ & 2.1 & $7 / 25$ & 1.7 & 6.2 & $9 / 15$ & $9 / 15$ & 7.6 & 0.33 \\
5 & 06 & $5 / 28$ & 4.4 & $6 / 4$ & $6 / 4$ & 0.1 & $7 / 17$ & 1.5 & $6 / 29$ & 1.5 & 7.5 & $9 / 12$ & $9 / 18$ & 7.9 & 0.37 \\
$(\mathrm{n}=7)$ & 07 & $5 / 26$ & 4.3 & $6 / 2$ & $6 / 15$ & 0.6 & $7 / 16$ & 1.9 & $7 / 25$ & 1.9 & 7.1 & $9 / 15$ & $9 / 19$ & 7.4 & 0.37 \\
6 & 06 & $5 / 25$ & 4.4 & $5 / 26$ & $5 / 30$ & 0.2 & $7 / 18$ & 2.1 & $7 / 28$ & 1.5 & 8.2 & $9 / 9$ & $9 / 12$ & 7.6 & 0.40 \\
$(\mathrm{n}=9)$ & 07 & $5 / 21$ & 3.9 & $5 / 27$ & $6 / 29$ & 2.0 & $7 / 20$ & 1.8 & $7 / 30$ & 1.5 & 7.2 & $9 / 11$ & $9 / 18$ & 7.3 & 0.44 \\
7 & 06 & $5 / 15$ & 6.1 & $5 / 20$ & $6 / 5$ & 0.9 & $7 / 18$ & 1.8 & $7 / 26$ & 0.7 & 9.3 & $9 / 9$ & $9 / 11$ & 7.8 & 0.28 \\
$(\mathrm{n}=9)$ & 07 & $5 / 15$ & 5.6 & $5 / 20$ & $6 / 5$ & 1.6 & $7 / 18$ & 2.4 & $7 / 27$ & 2.5 & 8.9 & $9 / 7$ & $9 / 11$ & 7.2 & 0.26 \\
\hline
\end{tabular}

(D: district, Y: year, FD: fertilizer application month/date, A: amount of nitrogen fertilizer [kg/ha], TD: transplanting date, TNF: total amount of nitrogen fertilizer [kg/ha], SD: sampling date, HD: harvesting date, P: protein content [\%], SD: standard deviation of protein content, " : vs. 2006 with $5 \%$ significant level)

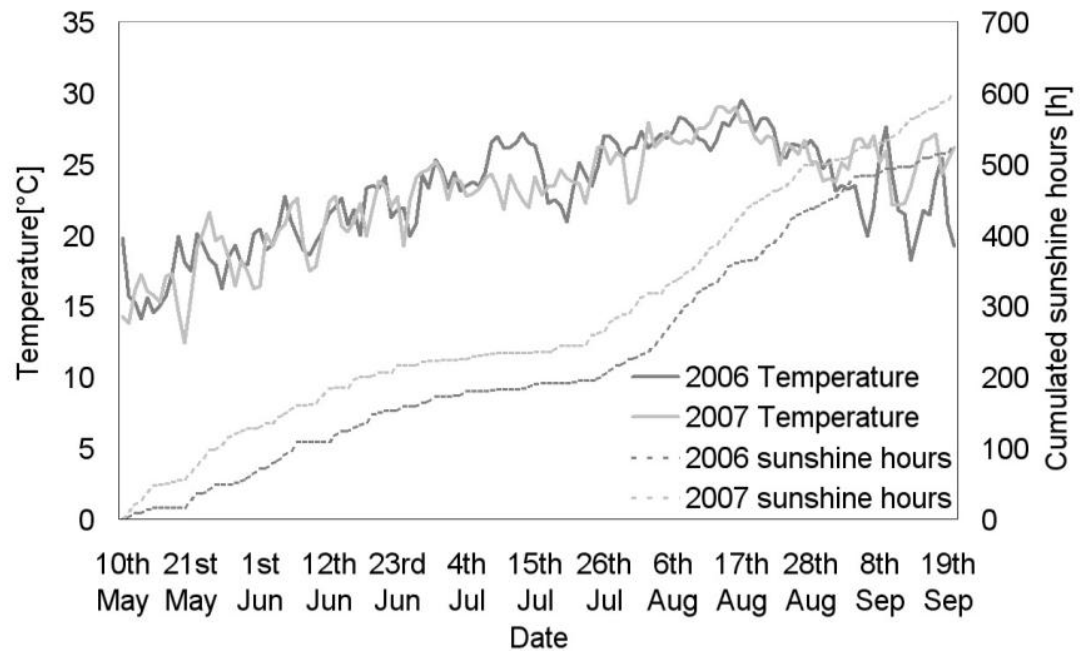

Fig. 2. Average temperature and cumulated sunshine hours from transplanting to harvest in 2006 and 2007 


\section{Modeling of protein contents}

The value of Field GreenNDVI was extracted using the overlay of the GreenNDVI raster file and the field shape file with $2 \mathrm{~m}$ of buffer zone, which was installed to exclude the mixed pixels between rice canopy and other parts of the field such as the field levee and the irrigation canal. The sampling point shape files in 2007 were also constructed using the GPS data and the value of Point GreenNDVI was also extracted using the overlay of the GreenNDVI raster file and the sampling point shape file with $1 \mathrm{~m}$ radius of buffer zone, which included the sampling point (Fig. 3). After the extraction, Field and Point GreenNDVI raster files were converted to vector files to calculate and analyze the GreenNDVI value of each field and sampling point. GreenNDVI values could not be extracted from seventeen fields in 2006 and eleven fields in 2007 due to the partial or entire cloud shadowing on the fields.
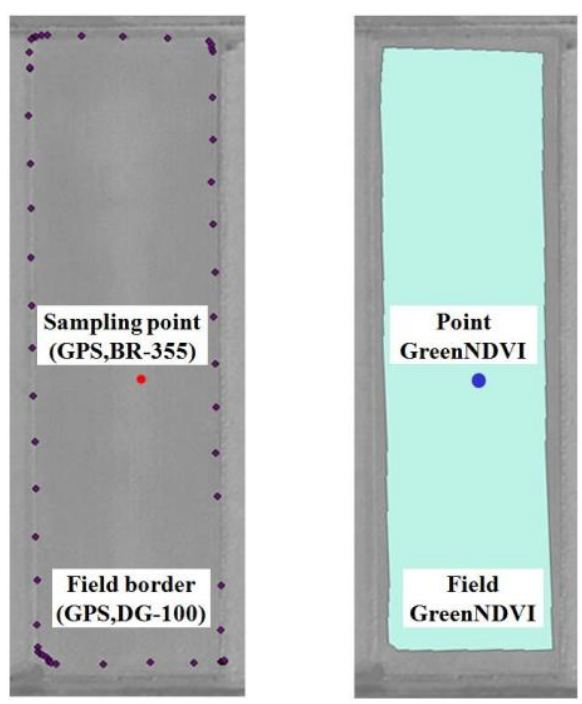

Fig. 3. Example of GPS points in field and extraction of point and field GreenNDVI

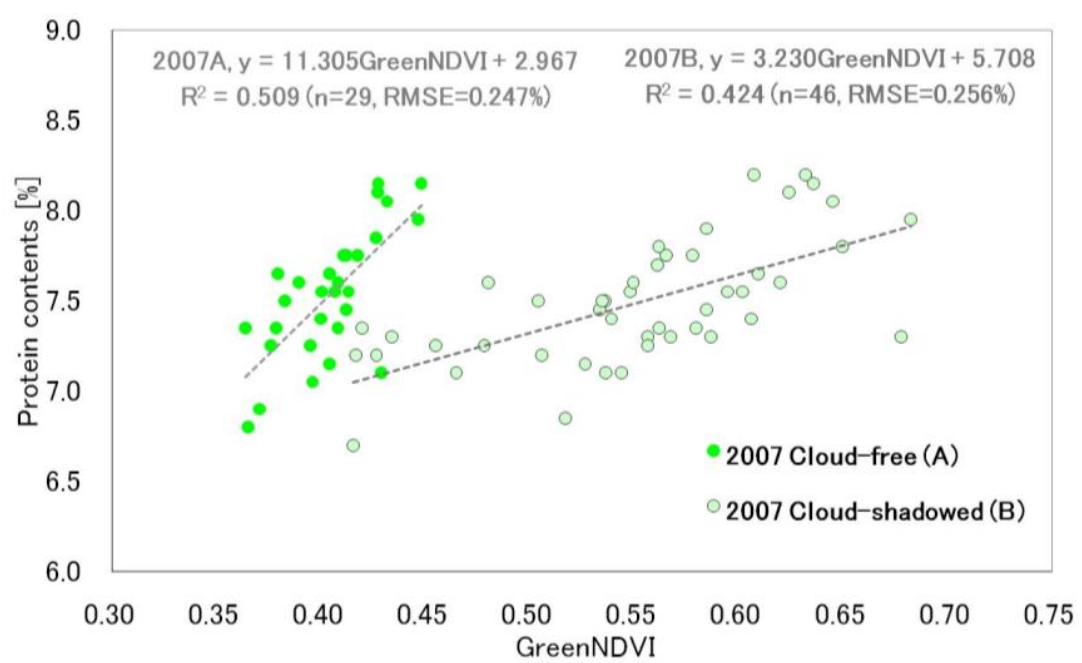

Fig. 4. Scatter plot of measured protein contents with average value of GreenNDVI at each sampling point 
However, it was possible to extract GreenNDVI values from the forty six cloudshadowed fields because not a portion but the entire district was covered by the cloud shadow in 2007.

The Point GreenNDVI model for cloud-free fields was established as $\mathrm{r}^{2}=0.509$, $\mathrm{n}=29, \mathrm{p}<0.01, \mathrm{RMSE}=0.247 \%$ (Fig. 4). In the case of that for the cloud-shadowed fields, the accuracy was as $\mathrm{r}^{2}=0.424, \mathrm{n}=46, \mathrm{p}<0.01, \mathrm{RMSE}=0.256 \%$. For the totally shadowed fields, it was also possible to establish the prediction model of PCs using the Point GreenNDVI value. However, the range of GreenNDVI for the cloud-shadowed fields was more than three times compared to that for the cloudfree fields. It is necessary to validate the model using the spatial or temporal data set to make the general-purpose prediction model.

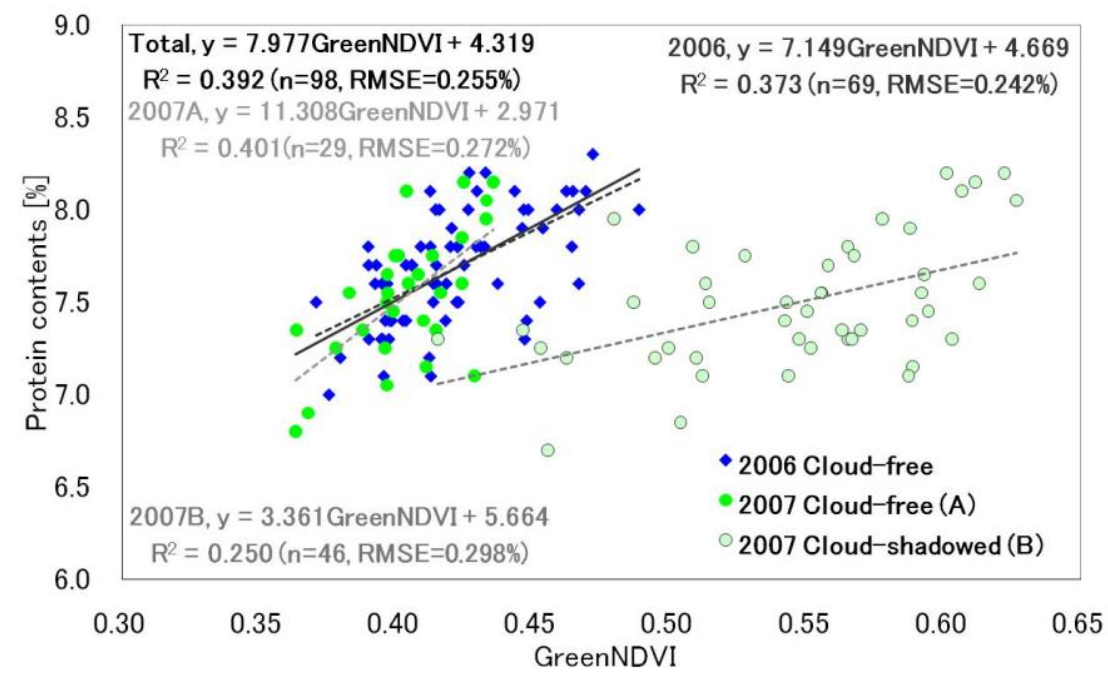

Fig. 5. Scatter plot of measured protein contents and average value of GreenNDVI in each field

The prediction model of PCs using Field GreenNDVI in 2006 was established as $\mathrm{r}^{2}=0.373, \mathrm{n}=69, \mathrm{p}<0.01, \mathrm{RMSE}=0.242 \%$ (Fig. 5). The model for the cloud-free fields in 2007 was also established as $\mathrm{r}^{2}=0.401, \mathrm{n}=29, \mathrm{p}<0.01, \mathrm{RMSE}=0.272 \%$. In the case of the cloud-shadowed fields in 2007, the accuracy of the model was $\mathrm{r}^{2}=0.250, \mathrm{n}=46, \mathrm{p}<0.01$, RMSE $=0.298 \%$. As shown in figure 5 , the slopes of the models for the cloud-free fields were similar to each other. Thus, the generalpurpose model, which was established using data from both years, was established as $\mathrm{r}^{2}=0.392, \mathrm{n}=98, \mathrm{p}<0.01$, RMSE $=0.255 \%$. Because the number of samples in 2006 was more than twice comparing with those in 2007, the slope of the generalpurpose model depended on the model in 2006. When the models of Point GreenNDVI were compared with that of Field GreenNDVI in 2007, the accuracy of the model for point GreenNDVI was higher than that of Field GreenNDVI. Therefore, the Point GreenNDVI model might be more suitable for prediction of $\mathrm{PC}$ around one week before harvest. 
It is necessary to confirm the extensiveness of the general-purpose model using data from different locations and growth conditions, such as on medium- and latematuring cultivars (Ryu et al. 2009).

\section{Analysis of GIS database}

Management information of one field in 2006 and thirteen fields in 2007 that are defective by the obscure date of the field management or fertilizer amount were excluded from the GIS database. The histogram showing the frequency distribution of PC in 2006 is similar to that in 2007 (Fig. 6). PCs were separated into two parts as shown in Fig 6;1) the upper part of the mean with half of the standard deviation (mean+0.5S.D.) and 2) the lower part of the mean with half of the standard deviation (mean-0.5S.D.). The key management factors between the upper and lower group were compared to find out the reason for the differing PCs.

There was a significant difference of PCs between the upper and lower parts depending on Factor 4 in 2007 (Table 3). It means that the PCs of the early harvested group are lower than those of the later harvested group; in other words, the quality of early harvested group is better.

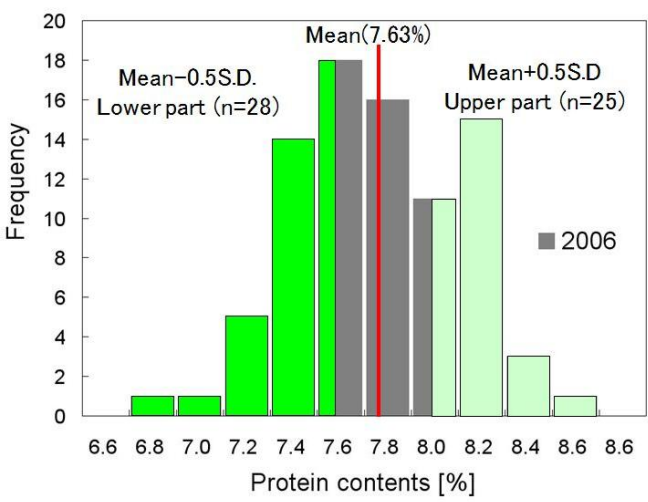

(a) protein contents in 2006

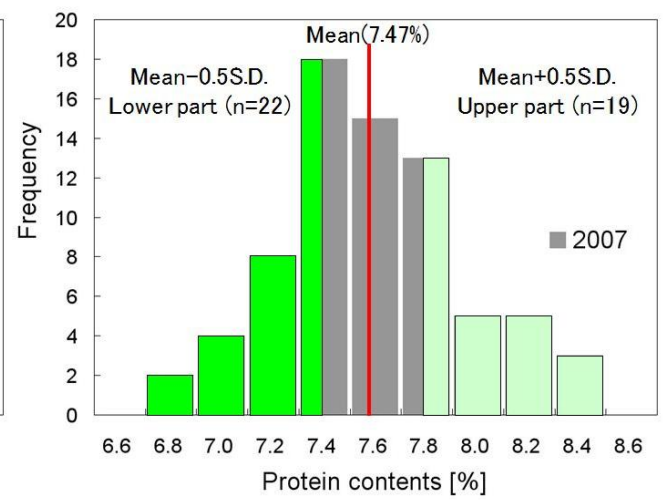

(b) protein contents in 2007

Fig. 6. Histograms of protein contents in 2006 and 2007

However, the results were different in 2006. They might be affected by the optimal timing for transplanting (Ueda et al. 1998), harvest (Matsue et al. 1991) and the weather condition as shown in Fig. 2. The effective cumulative temperature (ECT) was closely connected with the vegetation terms from transplanting to harvest (Fig. 7). In spite of the same variety, the transplanting date differed by three weeks (mid-May in 2006, early June in 2007) as shown in Table 2. The mean value of the ECT (MECT) from transplanting to harvest in 2006 was $967.7^{\circ} \mathrm{C}$ but in 2007 it was $974.5^{\circ} \mathrm{C}$ with two separated peaks (Fig. 7). Therefore, PCs in each year were separated into two groups depending on the MECT; (1) the upper group of MECT (UMECT) and (2) the lower group of MECT (LMECT) in order to reduce the difference of vegetation terms. 
Table 3 Statistical data for t-test and significant difference of protein contents depending on field management

\begin{tabular}{|c|c|c|c|c|}
\hline & & & 2006 & 2007 \\
\hline & Numbe & GIS database & 85 & 73 \\
\hline & Mea & n contents & 7.65 & 7.47 \\
\hline & & tion & 0.35 & 0.36 \\
\hline & & Number of samples & 25 & 19 \\
\hline Upp & r parts & Mean value & 8.07 & 7.94 \\
\hline & & Standard deviation & 0.15 & 0.18 \\
\hline & & Number of samples & 28 & 22 \\
\hline Low & r parts & Mean value & 7.26 & 7.07 \\
\hline & & Standard deviation & 0.17 & 0.18 \\
\hline & ECT & ig to first TOP (Factor 1) & 0.910 & 0.432 \\
\hline Significant of & ECT & ng to last TOP (Factor 2) & 0.793 & 0.397 \\
\hline t-test & Amol & rtilizer at TOP (Factor 3) & 0.553 & 0.308 \\
\hline & ECT & ing to harvest (Factor 4) & 0.966 & $0.020^{* * *}$ \\
\hline
\end{tabular}

(Lower parts: less than [mean - 0.5 S.D.], Upper parts: more than [mean + 0.5 S.D.], ECT: effective cumulative temperature, TOP: top-dressing, ${ }^{* *}: 5 \%$ of significant level)

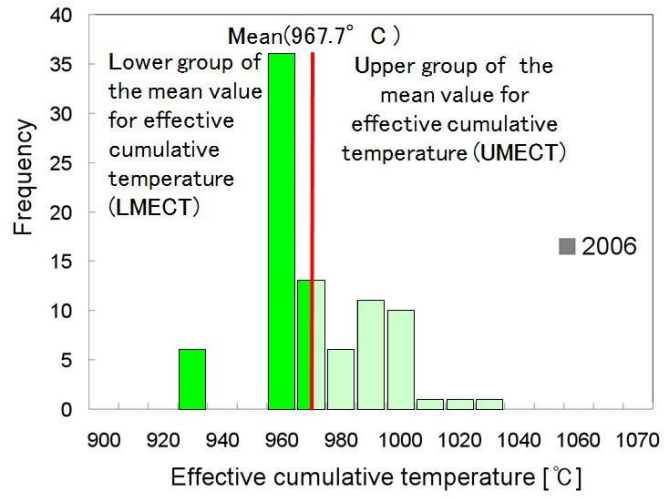

(a) effective cumulative temperature in 2006

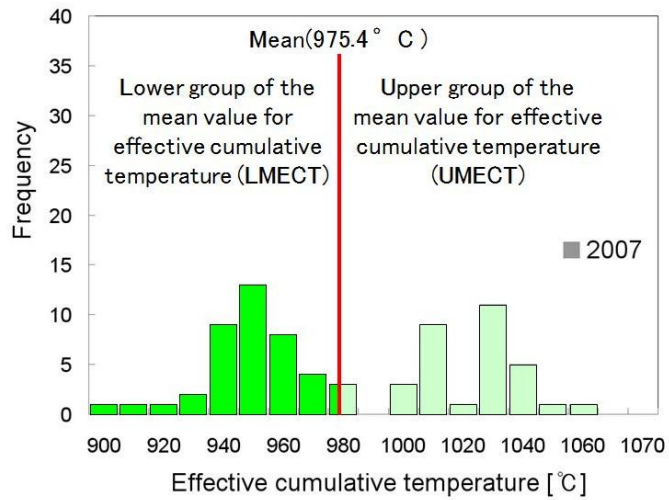

(b) effective cumulative temperature in 2007

Fig. 7. Histograms of effective cumulative temperature for each field in 2006 and 2007

Moreover, each group was separated into two parts to select the key management factors (Fig. 8). The range of PC at UMECT in 2006 was the same as in 2007, but the distribution was different. In LMECT, the range and distribution of PC were different between 2006 and 2007.

There was no significant difference in PCs between upper and lower parts at UMECT and LMECT in 2006 (Table 4). There was a significant difference between the upper and lower parts of PCs at LMECT in 2007 depending on the ECT from transplanting to last top-dressing (Factor 2). It might be possible to decrease PCs at harvest when the nitrogen fertilizer at top-dressing is applied earlier (Okadome et al. 1999). There was also a significant difference in 2007 at LMECT depending on the amount of nitrogen fertilizer at top-dressing (Factor 3). 

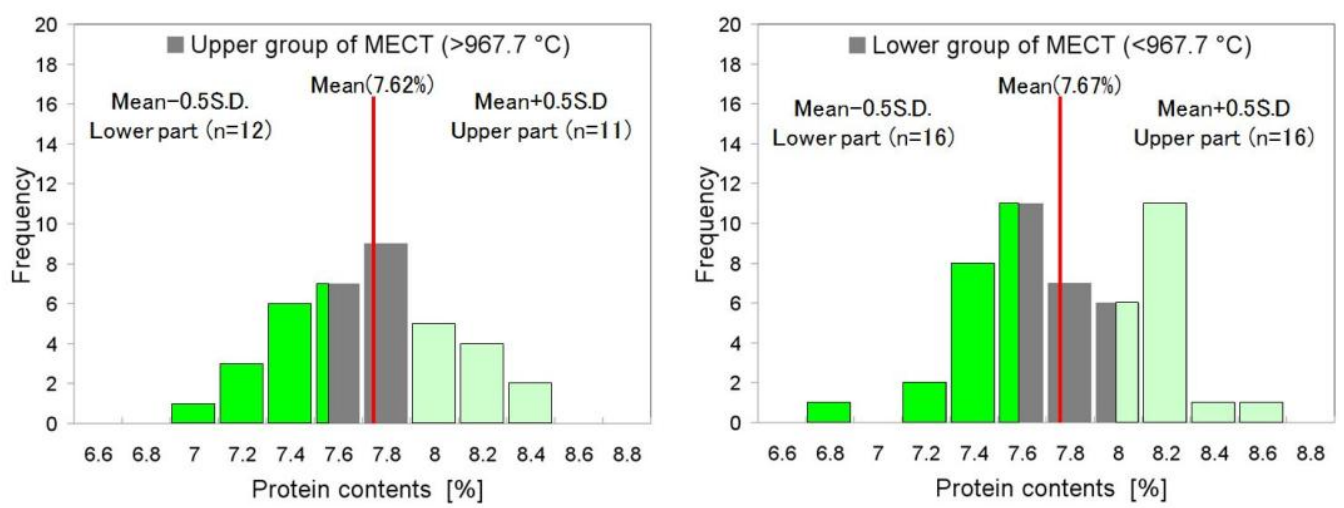

(a) protein contents in 2006 of UMECT

(b) protein contents in 2006 of LMECT
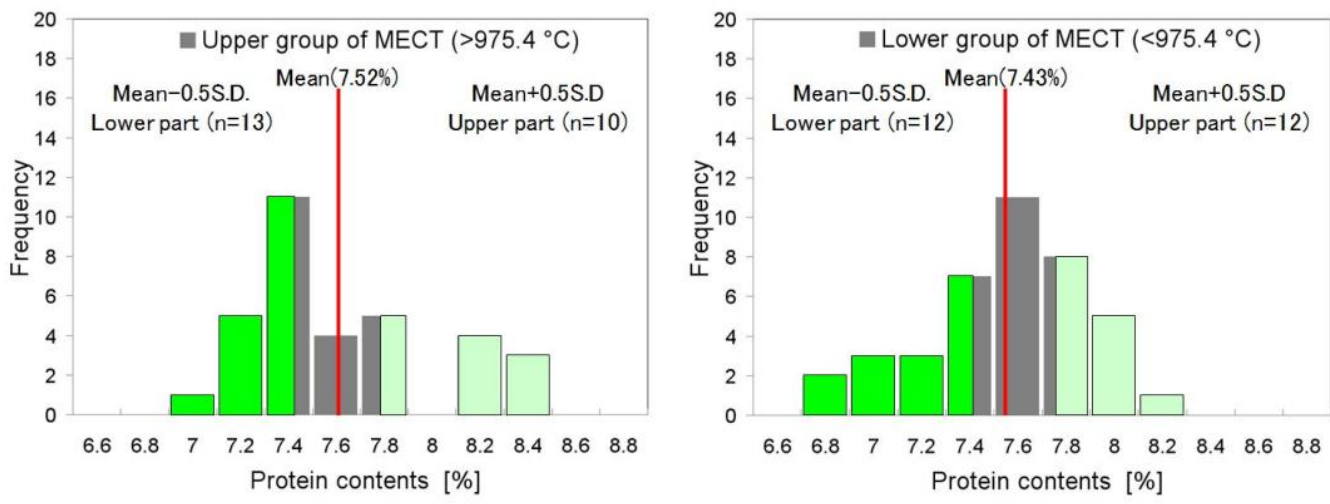

(c) protein contents in 2007 of UMECT

(d) protein contents in 2007 of LMECT

Fig. 8. Histograms of protein contents depending on upper and lower groups for mean value of effective cumulative temperature in 2006 and 2007

Table 4 Statistical data for t-test between lower and upper for mean of effective cumulative temperature and significant difference of protein contents depending on field management

\begin{tabular}{|c|c|c|c|c|c|c|}
\hline \multirow{2}{*}{\multicolumn{3}{|c|}{ Mean of effective cumulative temperature (MECT) }} & \multicolumn{2}{|c|}{$2006(967.7)$} & \multicolumn{2}{|c|}{2007 (975.4) } \\
\hline & & & \multicolumn{4}{|c|}{ LMECT UMECT LMECT UMEC? } \\
\hline \multicolumn{3}{|c|}{ Number of samples } & 50 & 35 & 40 & 33 \\
\hline \multicolumn{3}{|c|}{ Mean value } & 7.67 & 7.62 & 7.43 & 7.52 \\
\hline \multicolumn{3}{|c|}{ Standard deviation } & 0.35 & 0.35 & 0.34 & 0.39 \\
\hline \multirow{3}{*}{\multicolumn{2}{|c|}{ Upper parts }} & Number of samples & 16 & 11 & 12 & 10 \\
\hline & & Mean value & 8.06 & 8.02 & 7.79 & 8.03 \\
\hline & & Standard deviation & 0.14 & 0.19 & 0.14 & 0.20 \\
\hline \multirow{3}{*}{\multicolumn{2}{|c|}{ Lower parts }} & Number of samples & 16 & 12 & 12 & 13 \\
\hline & & Mean value & 7.29 & 7.23 & 7.02 & 7.17 \\
\hline & & Standard deviation & 0.20 & 0.14 & 0.21 & 0.13 \\
\hline \multirow{4}{*}{$\begin{array}{l}\text { Significant } \\
\text { of t-test }\end{array}$} & ECT fro & g to first TOP (Factor 1) & 0.564 & 0.124 & 0.776 & 0.162 \\
\hline & ECT fro & ng to last TOP (Factor 2) & 0.198 & 0.239 & $0.095^{*}$ & 0.249 \\
\hline & Amount & rtilizer at TOP (Factor 3) & 0.488 & 0.779 & $0.015^{* *}$ & 0.508 \\
\hline & ECT fr & ing to harvest (Factor 4) & 0.271 & 0.114 & $0.073^{*}$ & 0.348 \\
\hline
\end{tabular}

(LMECT: lower group of MECT, UMECT: upper group of MECT, Lower parts: less than [mean 0.5 S.D.], Upper parts: more than [mean + 0.5 S.D.], ECT: effective cumulative temperature, TOP: top-dressing, ${ }^{*}: 10 \%$ of significant level, ${ }^{* *}: 5 \%$ of significant level) 
It might be possible to decrease PC at harvest by reducing the amount of nitrogen fertilizer at top-dressing (Kusutani et al. 1992). There was a significant difference between the upper and lower parts of PCs at LMECT depending on Factor 4. It means that the PCs of the early harvested group are better than those of the later harvested group as shown in table 3.

When the farmers would have changed their field management, it would have been possible to decrease PCs in nineteen fields (27\%) in 2007. Although it might be possible to control PCs by field management factors, there are still controllable factors such as the term and timing of irrigation (Chen et al. 2003) and uncontrollable factors such as the amylose content and soil properties (Oosato et al. 1996). Therefore, it is necessary to accumulate the data on PCs with field management factors and increase the number of factors that affect rice quality to offer the identified information to farmers.

\section{Remote sensing and GIS database}

The possibility of selecting the key management factor directly using the GreenNDVI value was tested by the combination of remote sensing and GIS database. It was difficult to analyze using the data in 2007 because the image was influenced by the shadow of clouds, as mentioned before. Field GreenNDVI in 2006 was separated into the upper and lower parts (Fig 9a). There was no significant difference in the key management factors between the upper and lower parts (Table 5). A similar tendency was also shown that the difference in the key management factors was not significant in 2006 as shown in table 3.

Table 5 Statistical data for t-test and significant difference between GreenNDVI and protein contents depending on field management

\begin{tabular}{|c|c|c|c|}
\hline \multicolumn{2}{|r|}{2006} & \multicolumn{2}{|c|}{ GreenNDVI Protein content } \\
\hline \multicolumn{2}{|r|}{ Number of samples } & 69 & 69 \\
\hline \multicolumn{2}{|r|}{ Mean value } & 0.421 & 7.65 \\
\hline \multicolumn{2}{|r|}{ Standard deviation } & 0.026 & 0.30 \\
\hline \multirow{3}{*}{ Upper parts } & Number of samples & 18 & 18 \\
\hline & Mean value & 0.449 & 7.80 \\
\hline & Standard deviation & 0.012 & 0.26 \\
\hline \multirow{3}{*}{ Lower parts } & Number of samples & 24 & 24 \\
\hline & Mean value & 0.394 & 7.43 \\
\hline & Standard deviation & 0.009 & 0.22 \\
\hline \multirow{4}{*}{ Significant of t-Test $\frac{\mathrm{E}}{\mathrm{A}}$} & CT from transplanting to first TOP (Factor 1) & \multicolumn{2}{|c|}{0.316} \\
\hline & ECT from transplanting to last TOP (Factor 2) & \multicolumn{2}{|c|}{0.229} \\
\hline & Amount of nitrogen fertilizer at TOP (Factor 3) & \multicolumn{2}{|c|}{0.931} \\
\hline & ECT from transplanting to harvest (Factor 4) & \multicolumn{2}{|c|}{0.764} \\
\hline
\end{tabular}

(Lower parts: less than [mean - 0.5 S.D.], Upper parts: more than [mean + 0.5 S.D.], ECT: effective cumulative temperature, TOP: top-dressing) 
Therefore, Field GreenNDVI was separated into the UMECT and LMECT groups depending on the MECT and each group was also separated into the upper and lower parts as shown in Fig. 9b and 9c. There was a significant difference in LMECT between the upper and lower parts of Field GreenNDVI and PCs depending on the ECT from transplanting to first top dressing (Factor 1). There was also a significant difference in UMECT between the upper and lower parts of Field GreenNDVI and PCs depending on ECT from transplanting to harvest (Factor 4). It might be possible to decrease the PC in UMECT and LMECT depending on the timing of top-dressing and harvest. It means that it is possible to select the key management factors using the Field GreenNDVI. However, there were no significant differences between the upper and lower parts of the PCs depending on key management factors in the GIS database (Table 4).

Table 6 Statistical data for t-test between lower and upper for mean of effective cumulated temperature and significant difference of GreenNDVI depending on field management

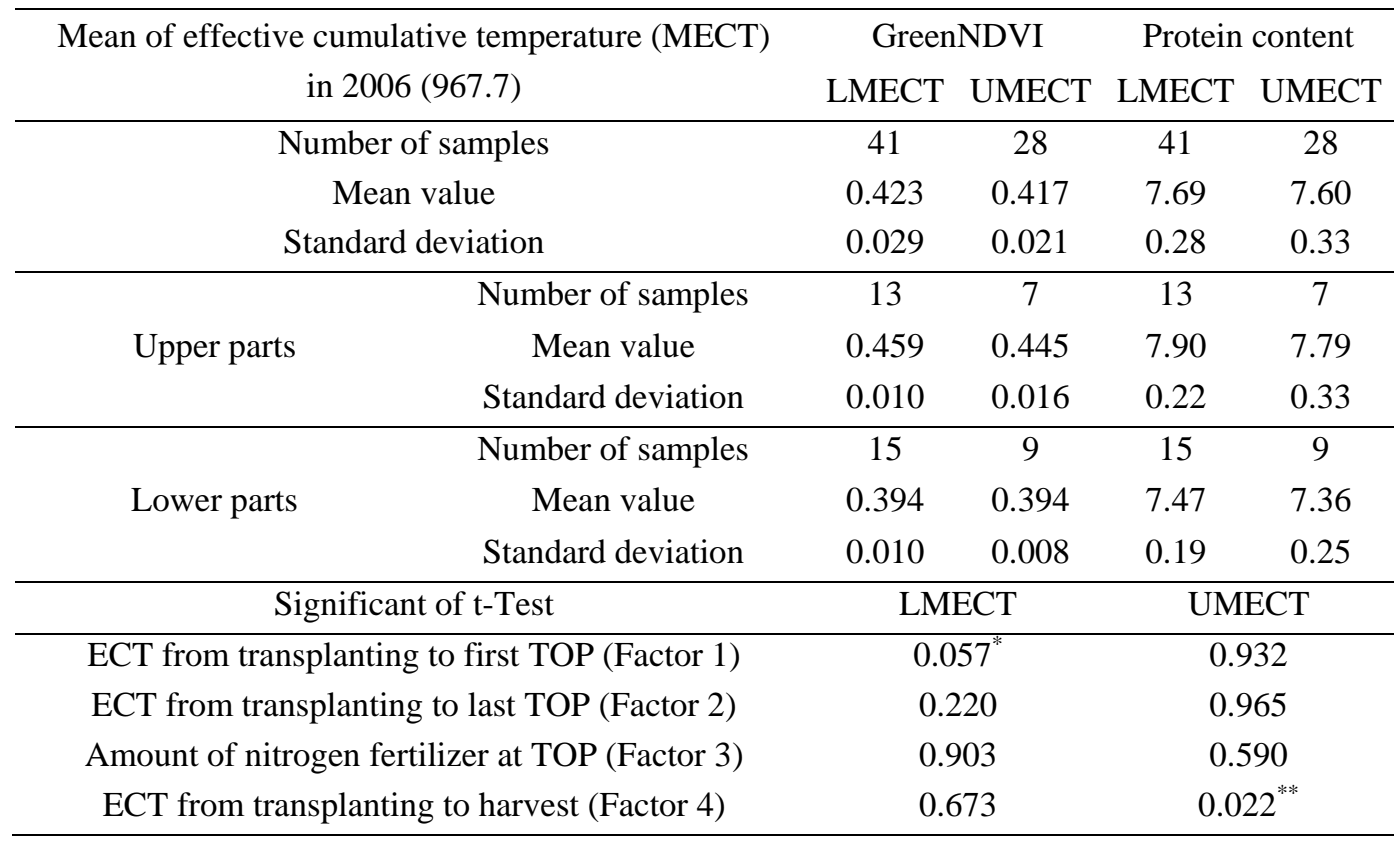

(LMECT: lower group of MECT, UMECT: upper group of MECT, Lower parts: less than [mean 0.5 S.D.], Upper parts: more than [mean + 0.5 S.D.], ECT: effective cumulative temperature, TOP: top-dressing, ${ }^{*}: 10 \%$ of significant level, ${ }^{* *}: 5 \%$ of significant level)

The difference in the results between Table 4 and Table 6 might be influenced by the difference in the number of samples between the analysis of GIS database (85 samples) and the analysis of the combination of remote sensing and GIS database (69 samples). Another reason might be that there was spatial variability not only in the PCs but also in the Field GreenNDVI. Nevertheless the PC was correlated with the Field GreenNDVI. 


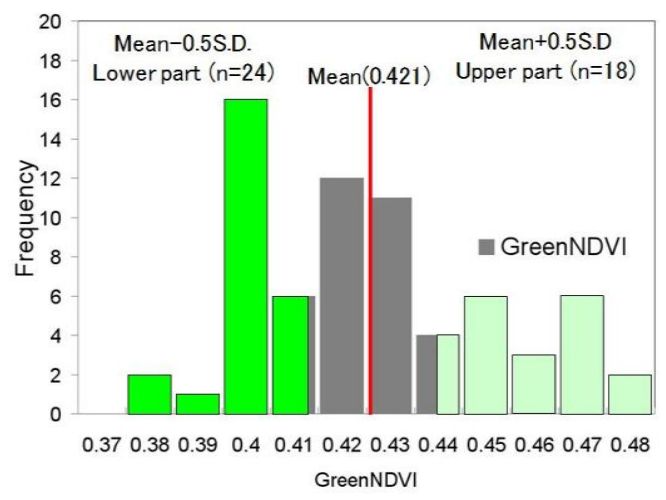

(a) GreenNDVI in 2006

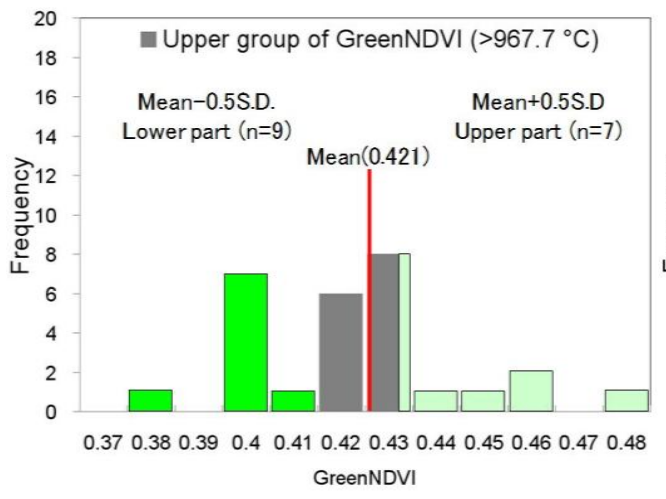

(b) GreenNDVI in 2006 of UMECT

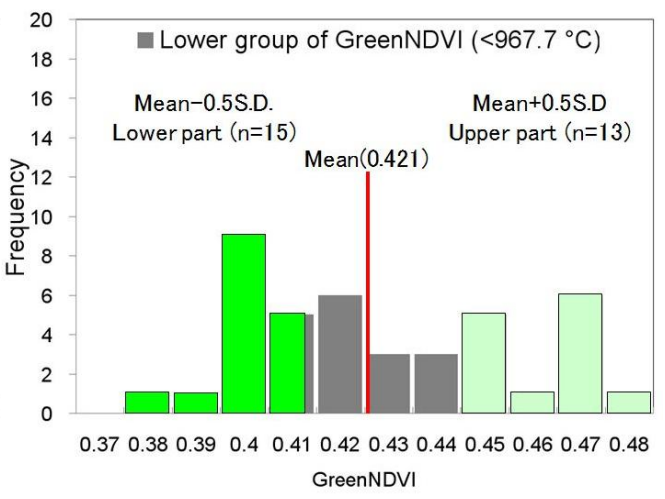

(c) GreenNDVI in 2006 of LMECT

Fig. 9. Histograms of GreenNDVI depending on upper and lower groups for mean value of effective cumulative temperature in 2006

One more challenge might be to distinguish the differences caused by the farmers' management factors that depend on their different approaches to farming (Roel et al. 2007). It might be also necessary to identify management zones based on the spatio-temporal homogeneity of soil properties and biomass data (Ikenaga and Inamura 2008) and to accumulate the relationship between grain yield and rice quality depending on the data from each farmer.

\section{Conclusions}

In this study, protein content (PC) of brown rice before harvest was established by remote sensing (RS) and analyzed to select the key management factors that cause the variation of PC using a GIS database. The combination of RS and GIS was tested to find out the key management factors using GreenNDVI.

There was spatial variability among districts and temporal variability in a given district with the same fields. PC was predicted by the average of GreenNDVI at sampling point (Point GreenNDVI) and in the field (Field GreenNDVI). The accuracy of the Point GreenNDVI model $\left(r^{2}>0.424\right.$, RMSE $\left.<0.256 \%\right)$ was better than that of the Field GreenNDVI model $\left(r^{2}>0.250\right.$, RMSE $\left.<0.298 \%\right)$. A generalpurpose model $\left(r^{2}=0.392, \mathrm{RMSE}=0.255 \%\right)$ was also established using two years data. 
In the GIS database, $\mathrm{PC}$ was separated into two parts to compare the difference in PC between upper (mean+0.5S.D.) and lower (mean-0.5S.D.) parts. Difference in PC was significant depending on the effective cumulative temperature (ECT) from transplanting to harvest (Factor 4) in 2007 but not in 2006. Because of the difference in ECT that depended on the vegetation term from transplanting to harvest, PC was separated into two groups based on the mean value of ECT as upper (UMECT) and lower (LMECT) groups. In 2006, there were no significant differences between the upper and lower parts not only UMECT but also LMECT. The difference in PCs at LMECT group between upper and lower parts was significant in 2007 and depended on the ECT from transplanting to last topdressing (Factor 2), the amount of nitrogen fertilizer at top-dressing (Factor 3) and Factor 4. When the farmers change their field management, it might have been possible to decrease the protein contents on nineteen fields (27\%) in 2007.

Using the combination of RS and GIS, it was possible to select the key management factors using Field GreenNDVI depending on the ECT from transplanting to the first top-dressing (Factor 1) at LMECT and Factor 4 at UMECT.

\section{Acknowledgments}

This work is financially supported by Nantan city, Kyoto prefecture, Japan. The author wishes to thank Nakagawa Yoshiteru, who was the manager of Yagi town agriculture public corporation during the experiments and is now an assistant for the head of section in Nantan-City.

\section{References}

Asaka, D., \& Shiga H., (2003), Estimating rice grain protein contents with SPOT/HRV data acquired at maturing stage, Journal of the Remote Sensing Society of Japan, 23(5), 451-457.

Chen, W., Zhang, G., Zhao, G., Yao, H., \& Xu, H., (2003), Variation in rice quality of different cultivars and grain positions as affected by water management, Field Crops Research, 80, 245-252.

Endo, I., Chikubu, S., Suzuki, M., Kobayashi, K., \& Naka, M., (1966), Palatability evaluation of cooked milled rice by physicochemical measurement, Report of National Food Research Institute, 31, 1-11.

Facchinelli, A., Sacchi, E., \& Mallen, L., (2001), Multivariate statistical and GISbased approach to identify heavy metal sources in soils, Environmental Pollution, 114, 313-324.

FAOSTAT, (2007), Statistical database of FAO, http://faostat.fao.org/site/567/default.aspx\#ancor Accessed 16 January 2009. 
Hache, C., Shibusawa, S., \& Sasao, A., (2005), Discriminating conventional and conservation agricultural management practices with airborne multispectral imagery, Agriculture, Ecosystems and Environment, 111, 354-366.

Hansen, P.M., Jorgensen, J.R., \& Thomsen, A., (2002), Predicting grain yield and protein content in winter wheat and spring barley using repeated canopy reflectance measurements and partial least squares regression, Journal of Agriculture Science, 139, 307-318.

Hansen, P.M., \& Schjoerring, J.K., (2003), Reflectance measurement of canopy biomass and nitrogen status in wheat crops using normalized difference vegetation indices and partial least squares regression, Remote sensing of Environment, 86, 542-553.

Ikenaga, S., \& Inamura, T., (2008), Evaluation of site-specific management zones on a farm with 124 contiguous small paddy fields in a multiple-cropping system, Precision Agriculture, 9(3), 147-159.

Iverson, L.R., \& Risser, P.G., (1987), Analyzing long-term changes in vegetation with geographic information system and remotely sensed data, Advance Space Research, 7(11), 194-194.

Japan meteorological Agency, (2007), the past meteorological data, http://www.data.jma.go.jp/obd/stats/etrn/index.php Accessed 16 January 2009.

Kawamura, S., Natsuga, M., Takekura, K., \& Itoh, K. (2003). Development of an automatic rice-quality inspection system. Computers and Electronics in Agriculture, 40, 115-126.

Kennedy, G., \& Burlingame, B., (2003). Analysis of food composition data on rice from a plant genetic resources perspective, Food Chemistry, 80, 589-596.

Koutroubas, S.D., Mazzini, F., Pons, B., \& Ntanos, D.A. (2004). Grain quality variation and relationships with morpho-physiological traits in rice (Oryza sativa L.) genetic resources in Europe. Field Crops Research, 86, 115-130.

Kusutani, A., Asanuma, K., Kogure, K., Seki, M., Hirata, S., \& Yangihara, T., (1992), Yield and eating quality of rice cultivar kinuhikari in early season culture in warmer area, Japanese Journal of Crop Science, 61(4), 603-609.

Martin M., \& Fitzgerald, M.A., (2002), Proteins in rice grains influence cooking properties, Journal of Cereal Science, 36, 285-294.

Matsue, Y., (1995), Studies on palatability of rice in northern Kyushu, Japanese Journal of Crop Science, 64(4), 714-716.

Matsue, Y., Furuno, K., \& Yoshida, T., (1991), Studies on palatability of rice in northern Kyushu, Japanese Journal of Crop Science, 60(4), 497-503.

Nagatsuka, S. \& Okazaki, M., Soil map of Japan, Central Japan,

http://eusoils.jrc.ec.europa.eu/esdb archive/EuDASM/Aisa/maps/JP2002 2SO.htm Accessed 16 January 2009.

Okadome, H., Kurihara, M., Kusuda, O., Toyoshima, H., Kim, J.I., Shimotsubo, K., Matsuda, T., \& Ohtsubo, K., (1999), Multiple measurement of physical 
properties of cooked rice grains with different nitrogenous fertilizer, Japanese Journal of Crop Science, 68(2), 211-216.

Oosato, K., Hamachi, Y., Matsue, Y., \& Yoshida, T., (1996), Genotype x environment interaction of palatability in rice, Japanese Journal of Crop Science, 65(4), 585-589.

Pettersson, C.G., Soderstrom, M., \& Eckersten, H., (2006), Canopy reflectance, thermal stress, and apparent soil electrical conductivity as predictors for withinfield variability in grain yield and grain protein of malting barley, Precision Agriculture, 7(5), 343-359.

Pierce, F.J., \& Clay, D., (2007), GIS applications in agriculture, Taylor \& Francis group, Boca Raton, FL, USA.

Roel, A., Firpo, H., \& Plant, R.E., (2007), Why do some farmers get higher yields? Multivariate analysis of a group of Uruguayan rice farmers, Computers and Electronics in Agriculture, 58, 78-92.

Rowshon, M.K., Kwok, C.Y., \& Lee, T.S., (2003), GIS-based scheduling and monitoring of irrigation delivery for rice irrigation system - Part I. Scheduling , Agriculture Water Management, 62, 105-116.

Ryu, C.S., Iida, M., Nishiike, Y., \& Umeda, M., (2005), Influence of several doses of nitrogen fertilizer on rice taste and grain yield, Journal of the Japanese Society of Agricultural Machinery, 67(6), 55-61.

Ryu, C.S., Iida, M., Suguri, M., Umeda, M., Inamura, T., Inoue, H., Shinjo, H., \& Moritsuka N., (2004), Effect of variable rate fertilizer application aimed reducing the spatial variability of grain yield on rice taste, Journal of the Japanese Society of Agricultural Machinery, 66(5), 49-62.

Ryu, C.S., Suguri, M., Iida, M., \& Umeda, M., (2007), Validation of rice taste elements influenced by amount of nitrogen fertilizer and estimation using remote sensing, Journal of the Japanese Society of Agricultural Machinery, 69(1), 52-58.

Ryu, C.S., Suguri, M., Umeda, M., (2009), Model for predicting the nitrogen content of rice at panicle initiation stage using data from airborne hyperspectral remote sensing, Biosystems Engineering, 104, 465-475.

Sophocleous M., (1992), Groundwater recharge estimation and regionalization the Great Bend Prairie of central Kansas and its recharge statistics-, Journal of Hydrology, 137, 113-140.

Tamaki, M., Ebata, M., \& Tashiro, T., (1989), Physico-ecological studies on quality formation of rice kernel, Japanese Journal of Crop Science, 58(4), 653658 .

Ueda, K., Kusutani, A., Asanuma, K., \& Ichii, M., (1998), Effect of transplanting timing on growth of rice cultivar kinuhikari in Kagawa Prefecture, Japanese Journal of Crop Science, 67(3), 289-296. 
Volkers, K.C., Wachendorf, M., Loges, R., Jovanovic, N.J., \& Taube, T., (2003), Prediction of the quality of forage maize by near-infrared reflectance spectroscopy, Animal Feed Science and Technology, 109, 183-194.

Wada, T., Oosato, K.F., \& Hamachi, Y., (2002), Effects of high air temperature and insufficient solar radiation during ripening period on the palatability and physicochemical properties of rice in 1999 in Kyushu regions, Japanese Journal of Crop Science, 71(3), 349-354. 